\title{
HCG trigger versus GnRH agonist trigger in PCOS patients under- going IVF cycles: frozen embryo transfer outcomes
}

\author{
Krishna Deepika ${ }^{1}$, Rathore Suvarna ${ }^{1}$, Maria Sumi ${ }^{1}$, Dhoble Snehal ${ }^{1}$, Vohra Arveen ${ }^{1}$, Kamath Anuja ${ }^{1}$, Pranesh \\ Gautham $^{1}$, Rao Kamini ${ }^{1}$ \\ 1Milann, the fertility Centre, Bangalore, India
}

Poster presentation at the ASRM 2019 Scientific Congress and Expo held in Philadelphia

\begin{abstract}
Objective: The use of Gonadotrophin releasing hormone agonist (GnRHa), with freeze-all strategy followed by frozen embryo transfer (FET) has been found to eliminate the risk of ovarian hyperstimulation syndrome (OHSS) in women with polycystic ovarian syndrome (PCOS) undergoing IVF cycles. However, physicians still hesitate to routinely use GnRHa as a trigger, replacing human chorionic gonadotrophin (hCG), for concerns of compromised cycle outcome. We aimed to evaluate outcomes following the transfer of embryos in FET cycles obtained from GnRHa trigger in comparison with hCG trigger in PCOS patients of Asian origin.
\end{abstract}

Methods: Prospective observational cohort study. 210 PCOS patients undergoing IVF in an antagonist protocol who were randomized in the previous study (to evaluate if GnRHa trigger is a better alternative than hCG in PCOS patients to prevent OHSS; Group A: GnRHa trigger $(n=92)]$ and Group B: hCG trigger $(n=101)]$, were followed up in FET cycles to assess the outcomes.

Results: The odds of cumulative live birth rate per stimulation cycle favors GnRHa trigger against the hCG trigger $[\mathrm{OR}=2.15$; (CI 1.2-3.83); $p=0.008]$. A significantly higher number of mature oocytes $(19.1 \pm 11.7$ versus $14.1 \pm 4.3 ; p<0.001)$ and blastocysts $(4.2 \pm 1.63$ versus $3.26 \pm 1.22 ; p<0.001$ ) were available in the GnRHa group as compared to the hCG group.

Conclusion: The cumulative live birth rate was better following transfer of frozen-thawed embryos generated from GnRHa-triggered cycles compared to hCG trigger. Hence, in PCOS undergoing IVF, as a good practice point, hCG trigger should be replaced by a GnRHa trigger with vitrification of all embryos followed by FET.

Keywords: GnRHa trigger, hCG trigger, PCOS, FET, live birth rate

\section{INTRODUCTION}

There has been an exponential increase in the number of Assisted Reproductive technology (ART) cycles (Toner et al., 2016), which has led to an increase in the incidence of ovarian hyperstimulation syndrome (OHSS), causing a threat to clinicians (Humaidan et al., 2010a). In IVF cycles following ovarian stimulation, the mild form of OHSS accounts for 20-33\% (Humaidan et al., 2013; Yen et al., 1968), moderate to severe being $3 \%$ to $8 \%$, which increases to $10-20 \%$, in a high risk population of PCOS (Delvigne \& Rozenberg, 2002; Nastri et al., 2015). Moderate and severe OHSS patients are of concern, with attendant morbidity (Papanikolaou et al., 2006) and mortality in cases of severe OHSS (Delvigne \& Rozenberg, 2002), with one death for every 50,000 treatment cycles as per the World Health Organization report (Hugues, 2001; Şükür et al., 2017). The culprit for this devastating complication is hCG, "The king", which has ruled the ART kingdom for more than three decades as ovulation trigger (Humaidan \& Polyzos, 2014). There is worldwide emphasis on the need to eliminate OHSS and one of the most effective strategy for this would be the use of GnRHa, as an alternative trigger for final oocyte maturation. GnRHa has revolutionized ART in the last decade, as it significantly reduces, or nearly eliminates the risk of OHSS (Engmann et al., 2006; 2008; DiLuigi et al., 2010; Humaidan et al., 2010a) in women with PCOS undergoing IVF cycles.

However, there still has been reservations concerning the use of GnRHa as a trigger routinely in all PCOS women undergoing IVF cycles for the prevention of OHSS, because of concerns of lower pregnancy rates (Humaidan et al., 2005; Kolibianakis et al., 2005), with reports on the outcomes, being conflicting. The causes of lower pregnancy rates, could probably, be due to sub-optimal yields of mature oocytes, with few cases of immature oocyte syndrome and empty follicle syndrome (EFS) reported (Honnma et al., 2011; Castillo et al., 2012), possible adverse effects on oocyte, embryo, endometrium and luteal phase. Although there has been a lot of supporting evidence in the literature to demonstrate that GnRHa trigger hampers embryo implantation due to rapid luteolysis, with associated luteal phase defects (Beckers et al., 2003; Kol, 2004; Humaidan et al., 2012), rather than developmental inability of the oocyte/embryos. Modified luteal support has been considered following embryo transfer in a fresh cycle, which can improve success rates (Humaidan et al., 2010b; Iliodromiti et al., 2013; Engmann et al., 2006; 2008), but this may come at a cost of increasing the risk of OHSS (Seyhan et al., 2013). Therefore, elective cryopreservation of all the embryos followed by a subsequent transfer, presents as a more rational approach in PCOS management. Furthermore, pregnancy rates after frozen embryo transfer following GnRHa has been shown to be comparable with hCG triggered cycles (Eldar-Geva et al., 2007; Griesinger et al., 2007; Herrero et al., 2011).

Despite this assurance, there still has been reluctance on the part of clinicians, including us, to replace hCG trigger even in indicated cases of PCOS and hyper-responders as a worldwide survey has shown that GnRHa trigger is used only in $5.2 \%$ to $36.1 \%$ of cases (Engmann et al., 2016). There is a need for greater clarity on the outcomes of frozen-embryos obtained from GnRHa triggered cycles in comparison with hCG trigger in terms of cumulative probability of achieving a live birth through consecutive transfers of these vitrified-warmed embryos. In addition, the study also intended to evaluate the embryological outcomes in terms of oocyte maturity, developmental and implantation ability of the embryos in both the groups. 


\section{MATERIALS AND METHODS}

\section{Study design and participants}

This was a prospective, observational study conducted in a tertiary care center- Milann Fertility Center, Bangalore to assess the frozen-thawed embryo transfer cycle outcome following GnRHa trigger and hCG trigger in PCOS patients. In the previous randomized controlled trial carried out between May 2013 and November 2015 [comparing $\mathrm{GnRH}$ agonist with hCG trigger in an antagonist protocol for prevention of OHSS with freeze-all strategy; 210 PCOS patients were randomized; 92 subjects in Group A: GnRHa triggered $(n=92)$ and Group B: hCG triggered $(n=101)$ included for the final analysis (Deepika et al., 2016)], were followed up prospectively over a period of three years. All participants underwent subsequent frozen-thawed embryo transfer cycles, and the treatment outcome of these subjects is reported herein. Approval was obtained from the Institutional Ethical Committee (ECR/773/INST/KA/2012) and the participants signed an informed consent form.

\section{Patient population}

Inclusion criteria: (i) All PCOS [defined as per the ESHRE/ASRM Rotterdam criteria (Rotterdam ESHRE/ASRM-Sponsored PCOS Consensus Workshop Group, 2004) demonstrating two of three criteria:(a) Oligo or anovulation; (b) clinical and/or biochemical signs of hyperandrogenism; (c) polycystic ovaries, defined on ultrasonography as 12 or more follicles measuring $2-9 \mathrm{~mm}$ in diameter or increased ovarian volume $(>10 \mathrm{cc})$ ] undergoing first IVF cycle. (ii) Age 20-37 years; (iii) early follicular phase serum FSH concentration ( $<10.0 \mathrm{IU} / \mathrm{I})$; (iv) body mass index (BMI) $>18$ and $<30 \mathrm{~kg} / \mathrm{m}^{2}$; ( $\mathrm{v}$ ) presence of both ovaries; (vi) indication for in-vitro-fertilization (IVF)/intracytoplasmic injection (ICSI); (vii) stimulation in GnRH antagonist protocol; (viii) Freeze-all strategy.

Exclusion criteria: (i) Donor cycles using GnRHa trigger; (ii) Patients with hypogonadotropic hypogonadism; (iii) surgical retrieval of sperms.

\section{Ovarian stimulation}

Controlled ovarian stimulation was started on day $2 / 3$ of the cycle, with Recombinant Follicle stimulating hormone (R-FSH), (Gonal-F, Merck Serono) after performing follicle stimulating hormone (FSH), luteinizing hormone (LH), estradiol (E2), progesterone (P4), anti-mullerian hormone $(\mathrm{AMH})$ and a baseline transvaginal scan. The starting dosage was individualized (ranging 112.5 -175IU) and we used a flexible multiple dose antagonist protocol. With three lead follicles $\geq 17 \mathrm{~mm}$ in diameter, peak E2, $\mathrm{LH}$ and P4 concentrations were measured and final oocyte maturation was accomplished with a single dose of 0.2 mg of Triptorelin (Decapeptyl, Ferring), subcutaneously in group A; recombinant hCG (rhCG), (Ovitrelle, Merck Serono) $250 \mathrm{mcg}$ subcutaneously in group B. GnRHa was administered at least $12 \mathrm{~h}$ after the last dose of $\mathrm{GnRH}$ antagonist. Transvaginal ultrasound-guided oocyte retrieval was performed 35 hours after the trigger under intra venous sedation with a single lumen oocyte retrieval needle. We used a freeze-all strategy. Post pick-up, we followed all the subjects on days 4 and 7, to assess for OHSS.

\section{Cryopreservation and thawing}

Oocyte maturity was defined as the ratio of mature oocytes (MII oocytes) to the total number of oocytes collected. ICSI was performed in all cases as per the hospital's standard operating procedure. Fertilization was checked $18 \mathrm{~h}$ after ICSI, by the appearance of two pronuclei. The embryos were graded as per the Istanbul consensus: Grade 1 (Good): $<10 \%$ fragmentation, stage-specific cell size and no multinucleation. Grade 2 (Fair): $10-25 \%$ fragmentation, stage-specific cell size for majority of cells and no evidence of multinucleation. Grade 3 (Poor): severe fragmentation ( $>25 \%$ ), cellsize not stage-specific and evidence of multinucleation. Grade 1 and 2 embryos were taken as top quality embryos and grade 3 embryos were discarded. The blastocysts were graded as: 1-Early; 2-Blastocyst; 3-Expanded; 4-Hatched/ hatching; Inner cell mass: 1 (Good)- prominent, easily discernible, with many cells that are compacted and tightly adhered together; 2(Fair)- easily discernible, with many cells that are loosely grouped together; 3(Poor)- difficult to discern, with few cells; Trophectoderm: 1(Good)- many cells forming a cohesive epithelium; 2(Fair)-few cells forming a loose epithelium; 3(Poor)- very few cells. As a policy, split freezing was employed when more than 7-8 CG1 embryos were available on day 3,50\% of them were cryopreserved in the cleavage stage and the remaining were cultured to blastocyst and then frozen. The embryos were then vitrified by open system using cyro-lock with $15 \%$ ethylene glycol, 15\% dimethylsulphoxide (DMSO) and $0.5 \mathrm{~mol} / \mathrm{L}$ sucrose as cryoprotectants (Sage vitrification kit, Origio). For blastocysts, the blastocele was collapsed using laser (Octax, MTG) and then vitrified using the same protocol as described for day-3 embryos. The embryos selected for transfer were thawed on the day of transfer using 1.0M sucrose (Sage thawing kit, Origio). Following thawing, we assessed the embryo quality by morphologic evaluation. For cleavage embryos, blastomere survival of $\geq 50 \%$ (with clear cellular boundaries and no degeneration); and for blastocyst, the ability of the blastocele to re-expand within 2-6 $\mathrm{h}$ post thaw was identified as a viable embryo. If not, the embryos were taken as failure to survive and were discarded (Consensus, Istanbul). The survival rate of the embryos following thawing was calculated as the number of viable embryos to the number of those thawed.

\section{Frozen embryo transfer}

All FET cycles were performed in a hormone replacement cycle with a $6 \mathrm{mg}$ daily dose of orally administered estradiol (Progynova; Zydus Cadila, German Remedies). Patients were to start FET cycle within 3 months after oocyte pick-up. When the endometrium evaluated by transvaginal sonography (TVS) was $>8 \mathrm{~mm}$ with triple layer morphology, it was considered mature. This was followed by endometrial priming with 3 days of injectable progesterone (gestone 50mg; Ferring) for cleavage embryos and 5 days for blastocysts. If the endometrial thickness was $<7 \mathrm{~mm}$ on day 9, Oestrogel (Besins, Belgium) was added and the dose of estradiol was increased to $12 \mathrm{mg}$. If the endometrial thickness remained less than $7 \mathrm{~mm}$, in spite of prolonged estradiol priming, the cycle was cancelled. The maximum number of embryos thawed and transferred per FET cycle was three in cleavage embryos and two in blastocyst. The day of embryo transfer (D3 or D5) was a clinical decision made depending on the endometrial thickness and the availability of good-quality embryos. Embryo transfer (ET) was performed under ultrasound guidance using Cooks catheter (K-JETS-7017-SIVF, Cook Medical, Syndey IVF). Luteal phase supplementation was administered for 14 days with vaginal progesterone and estradiol, and continued until 10 weeks of gestation, when clinical pregnancy (CP) was achieved. The $\mathrm{CP}$ rate was calculated as the number of cases with evidence of at least one gestational sac by TVS, divided by the number of transfers. The implantation rate was expressed as the number of gestational sacs seen on TVS to the number of embryos transferred. Miscarriage was defined as first-trimester pregnancy loss occurring after the first documentation of pregnancy on ultrasound from the fifth to the sixth week of gestation, until the $12^{\text {th }}$ week, and miscarriage rate was defined as the number of miscarriage divided by the 
number of transfers. Live birth was defined as birth beyond the period of viability ( 28 weeks of gestation) and the live birth rate was the ratio of live births to embryo transfers. Every woman was followed up until the first live birth or until three transfers if sufficient embryos were available. The cumulative live birth rate was defined as the number of live births per patient after three frozen embryo transfer cycles or exhaustion of all available embryos before three embryo transfer cycles per stimulation cycle. FET attempts for a second live birth from the same initial treatment cycle were excluded.

\section{Outcome measures}

Primary outcome: Cumulative live birth rate.

Secondary outcomes: MII rate of oocytes, availability of top quality embryos on day 3 (Grade 1 and grade 2) and blastocysts on day 5 , OHSS rate, survival rate of cryopreserved embryos, implantation rate, clinical pregnancy rate, miscarriage rate and multiple birth rate.

\section{Statistical analysis}

We analyzed the data using the Statistical Package for Social Sciences, version 16.0 (SPSS, USA). The continuous variables were expressed as mean $\pm S D$, and the categorical values expressed as percentages were analyzed using the chi square test. Independent sample t-test was used for continuous variables, which had a normal distribution. We used the odds ratio to evaluate the association of outcomes across the groups. A $p$ value $<0.05$ was considered statistically significant.

\section{RESULTS}

Baseline and stimulation cycle characteristics

The baseline and stimulation characteristics were similar in both groups (Table 1). However, the number of dominant follicles $\geq 17 \mathrm{~mm}$, the number of intermediate follicles between 14 to $16 \mathrm{~mm}$ and peak E2 levels on trigger day was found to be significantly higher in group A, as compared to group B (Table 1).

\section{Embryological and cycle outcomes}

Table 2 summarizes the embryological and cycle outcomes in both groups. Although the blastocyst conversion was similar in both groups, a significantly higher number of blastocysts was available in group A. The incidence of moderate to severe OHSS in the hCG group was $37.6 \%$ and $0 \%$ in GnRHa group $(p<0.001)$.

\section{Clinical outcomes-FET}

Subjects entering the first FET were 92 in group $A$, and 101 in group B, with a total of 365 FET cycles carried out across the groups, (170 cycles in GnRHa and 195 cycles in hCG group) [Figure 1 . Subject Flow chart]. In total, we cancelled about 21 cycles $(12.3 \%)$ in group $A$ and 26 in group B $(13.3 \%)$. The reasons for cycle cancellation were suboptimal endometrium, fluid in the endometrial cavity, premature rise of progesterone were not statistically significant between the two groups. However, cycle cancellation due to poor quality embryos following thawing was significantly higher in the hCG group than in the GnRHa group $[(9 / 195=4.6 \%)$ versus $(2 / 170=1.2 \%) ;(p=0.056)]$, respectively. Individuals entering $2^{\text {nd }}$ and subsequently $3^{\text {rd }}$ FET were either those who had failed to achieve a live birth with surplus embryos frozen or those in whom the cycles were cancelled for various above-mentioned reasons. Accordingly, 193 patients underwent the first FET cycle, 128 patients underwent a second FET and 44 patients underwent a third FET cycle across both the groups. Of reference, patients following an FET cycle, who had failed to achieve a live birth, with frozen embryos, yet did not return for transfer was similar in both groups $(15 / 92=16.3 \%$ versus $18 / 101=17.8 \% p=0.78$ ). Almost all subjects following oocyte retrieval returned for their $1^{\text {st }} \mathrm{FET}$, except for one in group $B$, with a significant proportion being lost following a $2^{\text {nd }} \operatorname{FET}(n=13)$ and a $3^{\text {rd }}$ FET $(n=19)$ across the groups. Following failed FET cycles, four individuals $(4 / 193=2 \%)$ achieved spontaneous pregnancy. Table 3 summarizes the clinical outcomes of FET cycles.

Table 1. Baseline and stimulation characteristics

\begin{tabular}{|c|c|c|c|}
\hline Variables & Group A (GnRHa) $(n=92)$ & Group B (hCG) $(n=101)$ & $\boldsymbol{p}$ \\
\hline Age (years) & $29.1 \pm 3.8$ & $29.06 \pm 3.6$ & 0.940 \\
\hline Primary infertility $n(\%)$ & $54(58.7 \%)$ & $64(63.3 \%)$ & 0.513 \\
\hline Secondary infertility $n(\%)$ & $38(41.3 \%)$ & $37(36.7 \%)$ & 0.51 \\
\hline Duration of infertility & $6.8 \pm 2.8$ & $6.2 \pm 2.3$ & 0.168 \\
\hline Irregular menstrual cycles $n(\%)$ & $45(48.9 \%)$ & $51(50.5 \%)$ & - \\
\hline Clinical Hyper-androgenemia $n(\%)$ & $31(33.7 \%)$ & $36(35.6 \%)$ & - \\
\hline BMI $\left(\mathrm{kg} / \mathrm{m}^{2}\right)$ & $25 \pm 3.7$ & $24.9 \pm 3.8$ & 0.901 \\
\hline Day 2 FSH & $5.2 \pm 1.5$ & $5.1 \pm 1.3$ & 0.683 \\
\hline AFC $¥$ & $26.3 \pm 4.8$ & $25.1 \pm 4.5$ & 0.074 \\
\hline $\mathrm{AMH}^{£}(\mathrm{ng} / \mathrm{ml})$ & $5.7 \pm 2.8$ & $5.9 \pm 2.6$ & 0.561 \\
\hline Dosage of gonadotrophin & $1845 \pm 707$ & $2095 \pm 906$ & 0.127 \\
\hline Duration of stimulation & $10 \pm 1.2$ & $10 \pm 1.4$ & 0.876 \\
\hline $\mathrm{DF}^{\ddagger} \geq 17$ & $12.7 \pm 4.3$ & $10.9 \pm 2.9$ & 0.001 \\
\hline $\mathrm{IMF}^{\triangleright} 14-16 \mathrm{~mm}$ & $11.7 \pm 3.9$ & $9.9 \pm 3.3$ & 0.001 \\
\hline Peak Estradiol & $4678.1 \pm 1331$ & $3870.4 \pm 1556$ & 0.001 \\
\hline Peak Progesterone & $1.76 \pm 1.1$ & $1.39 \pm 1.1$ & 0.052 \\
\hline
\end{tabular}

$p<0.05$ = statistically significant. $\mathrm{AFC}^{\ddagger}$-Antral follicle count; $\mathrm{AMH}^{\ddagger}$-Anti-mullerian hormone; $\mathrm{DF}^{\ddagger}$-Dominant follicle; IMF $^{\grave{\gamma}}$ Intermediate follicle 
Table 2. Embryological and cycle outcomes

\begin{tabular}{|l|c|c|c|}
\hline Variables & $\begin{array}{c}\text { Group A (GnRHa) } \\
\text { (n=92) }\end{array}$ & $\begin{array}{c}\text { Group B (hCG) } \\
\text { (n=101) }\end{array}$ & p \\
\hline Number of oocytes & $23.5 \pm 7.8$ & $20.8 \pm 5.4$ & 0.006 \\
\hline Mature oocytes (MII) & $19.1 \pm 11.7$ & $14.1 \pm 4.3$ & $<0.001$ \\
\hline Fertilized oocytes (2PN) & $15.6 \pm 5.6$ & $11.7 \pm 3.6$ & $<0.001$ \\
\hline Top quality cleavage embryos & $12.9 \pm 3.32$ & $9.09 \pm 2.99$ & $<0.001$ \\
\hline Blastocysts & $4.2 \pm 1.63$ & $3.26 \pm 1.22$ & $<0.001$ \\
\hline Blastocyst conversion & $59.9 \%$ & $58.2 \%$ & 0.689 \\
\hline OHSS $n$ (\%) & $1(0.52 \%)$ & $91(47.4 \%)$ & $<0.001$ \\
\hline
\end{tabular}

Values are expressed as mean \pm SD. $p<0.05=$ statistically significant.

The mean endometrial thickness was comparable between the groups $(9.5 \pm 1.75$ versus $9.8 \pm 1.35 \mathrm{~mm}$, $p=0.07)$. The number of cleavage embryos and blastocysts thawed as well as transferred per cycle was comparable in both the groups (Table 3). Accordingly, 711 embryos were transferred, with 379 blastocysts and 332 cleavage embryos replaced in 318 cycles across the groups. The odds for overall survivability of embryos (cleavage + blastocyst) across the groups was 1.01 [(CI-0.66-1.57); $p=0.92]$. The CP rate following $1^{\text {st }} \mathrm{FET}(43 / 81=53 \%$ versus $36 / 87=41.4 \% ; p=0.13) ;$ following $2^{\text {nd }} F E T(27 / 50=54 \%$ versus $25 / 61=41 \% ; p=0.35)$; after $3^{\text {rd }}$ FET $(9 / 18=50 \%$ versus $9 / 21=42.8 \% ; p=0.77)$, in group $A$ and $B$, respectively. The odds of CP per ET was significantly higher in group $A[O R=1.59 ; C I(1.02-2.48) ; p=0.04]$. The odds of cumulative $\mathrm{CP}$ per patient per stimulation cycle was significantly higher in group A $[O R=2.69 ;$ CI (1.3-5.54); $p=0.006]$. The odds of implantation was found to favor the GnRHa group [OR=1.56; CI $(1.1-2.91) ; p=0.011]$. There were seven ectopic pregnancies $(7 / 318=2.2 \%$ per cycle started). The singleton live birth rate was $42.3 \%$ and that for multiple births was $16.8 \%$ ( $16.1 \%$ twins, $0.6 \%$ triplets) across the groups (Table 3 ).

The live birth rate per first FET cycle was $34.6 \%$ and $22.9 \%$ [OR=1.77; (CI 0.89-3.48); $p=0.097$ ] in the GnRHa and the hCG group, respectively, with no significant differences when assessed across individual FET cycles (cycles $2 \& 3$ ). The odds of cumulative live birth rate per patient starting a frozen embryo transfer cycle was found to favor the GnRHa trigger as compared with the hCG trigger [OR=2.15; (CI 1.2-3.83); $p=0.008]$.

\section{DISCUSSION}

HCG has lucratively been used as a surrogate for the endogenous mid-cycle luteinizing hormone (LH) surge in all IVF cycles for follicular maturation, because of its similarities with LH (Ascoli et al., 2002). However, the prolonged luteotropic action of hCG (Yen et al., 1968) increases the risk of OHSS in PCOS and in hyper-responders. GnRHa has emerged as an alternative trigger, due to its initial flare effect, releasing endogenous gonadotrophins from the pituitary. However, due to its considerably short-lasting $\mathrm{LH}$ surge (24-36 h), it causes rapid luteolysis (Humaidan et al., 2005; Kolibianakis et al., 2005), with a drastic fall in steroid hormones and vascular endothelial growth factor (VEGF), the cytokine primarily responsible for OHSS (Cerrillo et al., 2009). A beneficial result of this is that it reduces the incidence of OHSS, but the fear has been with compromised cycle outcomes and reduced pregnancy rates.

The compromised cycle outcome and reduced pregnancy following GnRHa trigger was attributed to the probable ill effects of GnRHa on the quality of oocyte, embryo and implantation potential of the embryo. Initial RCTs which compared the clinical outcomes of GnRHa and hCG triggers in normoresponders undergoing IVF (Fauser et al., 2002; Kolibianakis et al., 2005; Humaidan et al., 2005), reported significantly lower pregnancy rates and higher early pregnancy losses in the GnRHa group. With these disappointing outcomes, the studies were prematurely stopped (Kolibianakis et al., 2005; Humaidan et al., 2005). Further, a meta-analysis by Griesinger et al. (2006) reported that GnRH agonist trigger is associated with a significantly reduced likelihood of achieving a clinical pregnancy $(0.21$, $0.05-0.84 ; p=0.03)$, with a pregnancy rate of $7.9 \%$ and $29.9 \%$ per randomized patient and an early pregnancy loss rate of $67.6 \%$ and $12.7 \%$ in the GnRHa and hCG triggered groups, respectively. These worrying rates were postulated to be due to either poor oocyte/embryo quality or luteal phase deficiency. Later, it was demonstrated that the proportion of mature oocytes, fertilized oocytes, and embryos obtained from donors triggered with GnRHa was similar to that of hCG trigger (Shapiro et al., 2007; Erb et al., 2010). These embryos, when transferred to oocyte recipients, resulted in good implantation and pregnancy rates (Acevedo et al., 2006; Sismanoglu et al., 2009; Bodri et al., 2009; Melo et al., 2009), thereby discounting any detrimental effect of GnRHa on oocyte/embryo quality. The lower live birth rates (Humaidan et al., 2005; Kolibianakis et al., 2005) was found to be due to defective luteal phase as significantly lower levels of E2, P4, inhibin A, and inhibin pro-aC levels were observed, impairing the endometrial receptivity and implantation (Fauser et al., 2002; Humaidan et al., 2005; Nevo et al., 2003). Further, to substantiate the compromised outcome following $\mathrm{GnRHa}$ is more due to luteal phase defects, than due to ill-effects on the oocyte or embryo, it has been established that the clinical outcome following transfer of frozen-thawed embryos obtained in GnRHa triggered cycles was the same as in those cycles triggered with hCG (Eldar-Geva et al., 2007; Griesinger et al., 2007; Herrero et al., 2011). Although, these data provide convincing evidence, there is still some apprehensions concerning the use of GnRHa trigger, in terms of oocyte quality, embryo quality and live birth rates. Thus, our study intended to assess the live birth rate in a freeze-all strategy in PCOS, following the transfer of embryos triggered with GnRHa in comparison to those from hCG triggered cycles.

Our study found a statistically significant higher clinical pregnancy rate following the transfer of embryos obtained from the GnRHa group as compared with that from the hCG group in frozen-thawed cycles (Table 3 ). This could be associated with a higher number of oocytes retrieved, greater maturity, better fertilization, greater number of top quality embryos and a higher number of blastocysts obtained in the GnRHa group in comparison to the hCG 


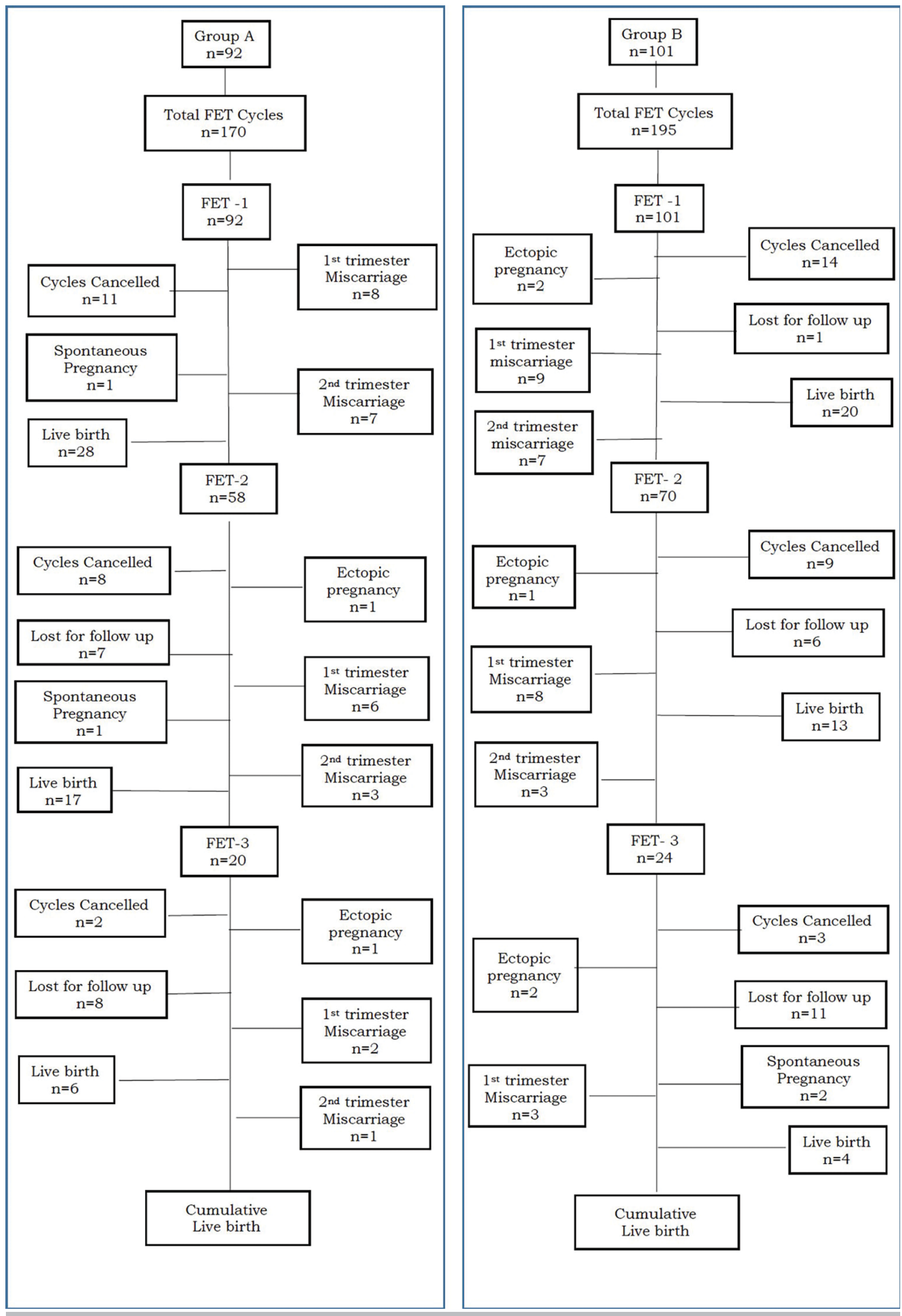

Figure 1. Subject flow chart 
Table 3. Clinical outcome-FET cycles

\begin{tabular}{|c|c|c|c|}
\hline Variables & $\begin{array}{c}\text { Group A (GnRHa) } \\
(n=92)\end{array}$ & $\begin{array}{c}\text { Group B (hCG) } \\
(n=101)\end{array}$ & p-value \\
\hline FET cycles attempted (365) & 170 & 195 & - \\
\hline FET cycles cancelled $n(\%)$ & (21/170) 12.3 & (26/195) 13.3 & 0.776 \\
\hline $\begin{array}{l}\text { FET cycles with cleavage/blastocyst } \\
\text { transfers } \\
\text { a. cleavage } n(\%) \\
\text { b. blastocyst } n(\%)\end{array}$ & $\begin{array}{c}(46 / 149) 30.8 \\
(103 / 149) 69.1\end{array}$ & $\begin{array}{l}(75 / 169) 44.3 \\
(94 / 169) 55.6\end{array}$ & $\begin{array}{l}0.013 \\
0.013\end{array}$ \\
\hline $\begin{array}{l}\text { Mean number of embryos thawed } \\
\text { a. cleavage } \\
\text { b. blastocyst }\end{array}$ & $\begin{array}{l}3.02 \pm 0.57 \\
2.15 \pm 0.53\end{array}$ & $\begin{array}{l}3.19 \pm 0.48 \\
2.16 \pm 0.40\end{array}$ & $\begin{array}{l}0.079 \\
0.881\end{array}$ \\
\hline $\begin{array}{l}\text { Survival rate } n(\%) \\
\quad \text { a. cleavage } n(\%) \\
\text { b. blastocyst } n(\%)\end{array}$ & $\begin{array}{l}(123 / 142) 86.6 \\
(198 / 221) 89.5\end{array}$ & $\begin{array}{l}(209 / 239) 87.4 \\
(181 / 203) 93.3\end{array}$ & $\begin{array}{l}0.815 \\
0.894\end{array}$ \\
\hline $\begin{array}{l}\text { Mean number of embryos transferred } \\
\text { a. cleavage } \\
\text { b. blastocyst }\end{array}$ & $\begin{array}{c}2.62 \pm 0.61 \\
1.92 \pm 0.3\end{array}$ & $\begin{array}{l}2.79 \pm 0.41 \\
1.93 \pm 0.26\end{array}$ & $\begin{array}{l}0.068 \\
0.803\end{array}$ \\
\hline Clinical pregnancy/ET $n(\%)$ & $(79 / 149) 53$ & (70/169) 41.4 & 0.039 \\
\hline Implantation rate $n(\%)$ & $(94 / 321) 29.2$ & $(82 / 390) 21$ & 0.011 \\
\hline Miscarriage rate $n(\%)$ & $(16 / 149) 10.73$ & $(20 / 169) 11.83$ & 0.757 \\
\hline Live birth per ET $n(\%)$ & $(51 / 149) 34.2$ & (37/169) 21.89 & 0.014 \\
\hline Singleton births $n(\%)$ & (38/79) 48.1 & $(25 / 70) 35.7$ & 0.127 \\
\hline Multiple births $n(\%)$ & $(13 / 79) 16.4$ & $(12 / 70) 17.1$ & 0.909 \\
\hline Cumulative live birth rate $n(\%)$ & $(51 / 92) 55.43$ & (37/101) 36.63 & 0.009 \\
\hline
\end{tabular}

expressed as number (percentage). $p<0.05=$ statistically significant

group. A higher number of follicles was observed in the GnRHa group, accounting for the retrieval of a higher number of oocytes reaching statistical significance. This difference in oocyte numbers may be a reflection of different responses from each individual between the two groups, which probably is a chance finding. Importantly, we witnessed an increase in MII oocytes (average of 5) retrieved in the GnRHa triggered group, adding to the impact on the clinical outcome. This could possibly, be the result of a physiological FSH surge, which induces the formation of $\mathrm{LH}$ receptors on the luteinizing granulosa cells, promoting nuclear maturation and cumulus expansion (Eppig, 1979; Humaidan et al., 2005; 2010b). The availability of top-quality cleavage embryos on day 3 was significantly higher in the GnRHa group (91.3\%) than the hCG group $(74.3 \%)$. In concordance, few trials have reported that the use of an agonist trigger produced comparable or slightly superior embryo quality compared with hCG trigger (Humaidan et al., 2009; 2010b; 2011; DiLuigi et al., 2010). The same has been substantiated in donor cycles, reporting a higher yield of good quality embryos in the GnRHa triggered group (Melo et al., 2009; Acevedo et al., 2006; Erb et al., 2010).

A better embryological outcome observed in the GnRHa group compared with the hCG group (Table 2 and 3), could be associated with the differences in the duration, profile and physiological events following the two triggers (Yding Andersen et al., 1993). LH and hCG differ in structural features, such as the presence of a carboxyl terminal peptide, the type and amount of glycosylation. The half-life of $\mathrm{LH}$ is shorter (60-120min), whilst the half-life of hCG exceeds $24 \mathrm{~h}$, exerting a higher biological activity. Because of these differences, although both LH and hCG act on the same receptor, luteinizing hormone-chorionic gonadotropin receptor (LHCGR), there is preferential activation of different signal transduction pathways and, eventually, different cell responses (Ulloa-Aguirre et al., 2011). LH is more active than hCG on pAKT and extracellular signal regulated kinase (ERK1/2) phosphorylation, causing granulosa cell proliferation and differentiation (Craig et al., 2007). Whilst, hCG is more active than LH in activation of cyclic AMP-protein kinase A (CAMP/PKA), steroidogenesis and potentially pro-apoptotic pathways (Casarini et al., 2012). HCG generates more intracellular cAMP accumulation and increases progesterone concentrations within the follicular fluid (Yding Andersen et al., 1993).

The longer hCG half-life and increased follicular fluid progesterone levels causes over-luteinization of the recruited follicles (Erb et al., 2010), affecting oocyte and embryo quality which is reflected by the finding of a higher number of poor quality embryos in the hCG group $26(25.7 \%)$, as compared to the GnRHa group $8(8.7 \%) ;(p=0.002)$. On the contrary, a higher number of top quality embryos on day 3 was seen in the GnRHa group, yielding a significantly higher number of blastocysts (Table 2). As a result, the GnRHa group had a statistically higher number of FET cycles with blastocyst transfer $(69.1 \%$ versus $55.6 \% ; p=0.014)$ than the hCG group. Gurbuz et al. (2016) showed that wherein time-lapse imaging of the embryos obtained from $\mathrm{Gn}$ $\mathrm{RHa}$, cleaved faster than the embryos obtained from hCG triggered cycles in antagonist protocols. It has been well established that early cleavage embryos results in a higher fraction of good-quality embryos and blastocysts (Cruz et al., 2012; Wong et al., 2010). Probably, a timelapse imaging would have enabled us to compare the exact morphokinetics of the embryos in both groups; it was not done in our study, due to non-availability of this facility.

The live birth rate in women at risk of OHSS triggered with GnRHa, where fresh transfer was carried out, intensifying luteal support was found to be comparable with that 
of frozen transfer, respectively $[27.1 \%$ and $20 \% ; p=0.4$, $\mathrm{RR}=1.36$ (0.65-2.81)] (Imbar et al., 2012). However, rescuing luteal phase with a bolus of hCG in women at risk of OHSS has resulted in a few cases of severe OHSS [2/ 275 (0.72\%) (Iliodromiti et al., 2013; 6/23 (26\%) Seyhan et al., 2013)]. Although, the luteal phase can be rescued to enable fresh ET following GnRHa trigger, the concerns, being, late onset OHSS, which tends to be more severe, compromised endometrial receptivity and an ideal (yet to be defined) luteal phase support. Additionally, vitrification has provided us exceptionally good survivability of embryos following thawing. Further, a meta-analysis by Roque et al. (2013) proved a significantly higher implantation and CP rates, a significantly higher ongoing pregnancy rate (Balaban et al., 2008), better obstetric and perinatal outcomes (Maheshwari et al., 2012) in FET cycles when compared to fresh ETs. Hence, we preferred to avoid fresh transfers, freeze all embryos and transfer them subsequently, the so-called segmentation strategy (Devroey et al., 2011; Garcia-Velasco, 2012). However, cycle segmentation might not be acceptable for all due to ethical, legal or social reasons, the addition costs involved in freezing and the risks to embryo viability during the freezing and thawing processes. Moreover, cryopreservation may produce alterations in the embryonic genome integrity, which are undetectable by traditional assays. Such modifications might have longterm implications of epigenetic disorders in children born from these vitrified embryos (Kopeika et al., 2015), with limited number of long-term follow-up studies until now.

Following thawing, the survival rate of vitrified embryos and the morphologic quality of vital embryos that were transferred were found to be similar in both the groups. Further, the survival rate of vitrified cleavage embryos in the GnRHa group $(86.6 \%)$, is within the range of the survival rates following hCG trigger, as reported by few other authors, as $70 \%$ to $95 \%$ (Balaban et al., 2008; Rezazadeh Valojerdi et al., 2009). Additionally, the survivability of vitrified blastocysts following GnRHa (89.5\%), is similar to that following hCG trigger as reported in two large studies, as $77 \%$ (Van Landuyt et al., 2011) and $85.7 \%$ (Takahashi et al., 2005). Further, the GnRHa group witnessed a higher implantation rate per FET cycle when compared to the hCG group (Table 3 ). The findings concur with the previous morphokinetics-based studies, wherein, it has been explicated that the proportion of competent embryos with higher implantation potential was significantly higher in the GnRHa group when compared with the hCG-triggered group (Fenwick et al., 2002; Lemmen et al., 2008; Wong et al., 2010).

Women undergoing up to three FET attempts were considered for the analysis, as the efficacy of further attempts is questionable, bearing in mind, the fact that good quality embryos would be transferred in the first few cycles. Thus, the highest $\mathrm{CP}$ rates were seen in the first and second cycles compared with the third one, establishing that patients with relatively good prognosis were more likely to achieve a live birth. Following three consecutive frozen transfers, remarkably, the cumulative live birth rate in the GnRHa group was $55.4 \%$ versus $36.6 \%$ in hCG group, and a trend of higher birth rates was consistently found in the GnRHa group (Figure 2). Thus, our study derives a meaningful aspect that about $55 \%$ of infertile PCOS patients achieved a live birth with one ovarian stimulation cycle following GnRHa trigger. Further, after three failed FET attempts, it could be that these patients could decrease their time to pregnancy either by considering pre-implantation screening of the remaining frozen embryos as a selection tool, or by starting a fresh ovarian stimulation cycle. It is noteworthy that a significant proportion of cumulative take-home babies came from the transfer of vitrified blastocysts $(60.7 \%$ and $62.1 \%$ ) across the groups. The cumulative live birth rate was higher with the transfer of

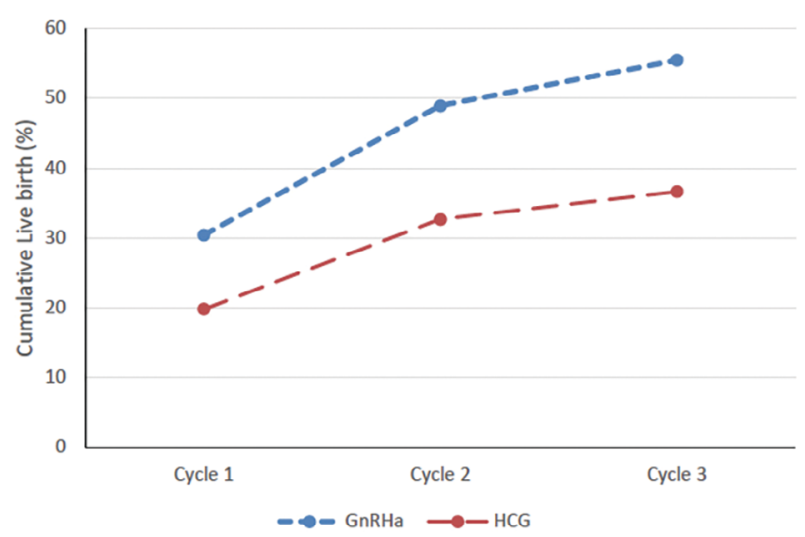

Figure 2. Cumulative Live birth rate per patient in FET cycles following GnRHa trigger (blue dotted line) and hCG trigger (red dotted line).

blastocysts (61.3\%) than cleavaged embryos (38.6\%), in both groups and thus, a live birth can be achieved earlier with blastocyst than with early stage embryo transfer.

The Live birth rate per FET cycle was $34.2 \%$ and $21.9 \%$ $[O R=1.86$ (CI 1.13-3.05); $p=0.015]$ in the GnRHa and the hCG group, respectively. A significant difference in the live birth rate per FET cycle was in favor of the GnRHa trigger, of $12.3 \%$. The live birth rate per FET reported in a large retrospective cohort study of 5,85,065 ART treatment cycles performed between 2002 and 2013 using the Australian and New Zealand Assisted Reproduction Database (ANZARD) was $23.3 \%$, the adjusted odds resulting in a live birth was 0.86 (95\% CI 0.82-0.90) (Chambers et al., 2016). In the Canadian ART Registry (CARTR), the takehome rate in 3,224 FET cycles in a non-selected patient population was $17.8 \%$ (Gunby et al., 2011). As per the HFEA report, the live birth rate per started FET cycle was $24.8 \%$ in 2013 (Human Fertilisation and Embryology Authority (HFEA), 2016). The live birth rates in FET cycles obtained from embryos following GnRHa trigger presented in this study are well above the range of that following the hCG trigger, as reported in the various large-scale studies mentioned above. The favorable outcome associated with the FET cycles following GnRHa trigger is the result of better oocyte maturity and better quality embryos, with developmental potential. We thus uphold the recommendation that a time has come for a paradigm shift in triggering policy, replacing hCG, endorsing the statement by Humaidan, "The King is dead, long live the King" (Humaidan \& Alsbjerg, 2014; Humaidan \& Polyzos, 2014).

The strengths of the study being, homogenous select population of PCOS, comparing the outcome of FETs following GnRHa and hCG trigger in a freeze-all cycle, without any negative influence of fresh transfer, avoiding confounding biases. The power of randomization present in the initial study (Deepika et al., 2016) has still been preserved in this observational study, because the same set of subjects were followed up as FET cycle without any impact on the baseline risk for accomplishment of live births. The study derives more precise estimates of the outcomes of interest, the cumulative live birth rates and embryological outcomes in both the groups. Limitations of the study being, the population included moderately younger age

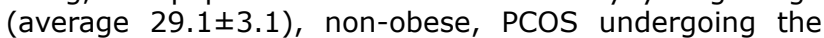
first IVF cycle with substantially good prognosis. Although a good number of top quality embryos were available on day 3 , all of them could have been cultured to blastocyst and then frozen, instead of split freezing which could have 
minimized bias. Because of this, the study included both cleavage and blastocyst transfers across the groups. However, this lack of homogeneity is less likely to significantly affect our findings. The obstetric, neonatal and importantly, the long-term outcomes of children will be of immense value, a subsequent analysis being planned in the near future.

In conclusion, the transfer of frozen-thawed embryos obtained from GnRHa-triggered cycles in PCOS resulted in higher cumulative live birth rate compared with the hCG trigger. Triggering with $\mathrm{GnRHa}$, yielded more mature oocytes and better quality embryos with a higher developmental potential. Adopting GnRHa as a routine trigger policy in PCOS, is physician and patient friendly, as it provides a better cycle outcome, almost abolishing the risk of OHSS.

\section{ACKNOWLEDGEMENTS}

The authors would like to thank all the postdoctoral fellowship students, consultants, and paramedical staff at Milann, The fertility center, for their invaluable support in generating this manuscript.

\section{CONFLICT OF INTEREST}

The authors have no conflict of interest to declare.

\section{Corresponding autor:}

Krishna Deepika

Senior Consultant in Reproductive Medicine

Milann, the Fertility Centre

Bangalore-India.

E-mail: drkdeepika@rediffmail.com

\section{REFERENCES}

Acevedo B, Gomez-Palomares JL, Ricciarelli E, Hernandez ER. Triggering ovulation with gonadotropin-releasing hormone agonists does not compromise embryo implantation rates. Fertil Steril. 2006;86:1682-7. PMID: 17074344 DOI: $10.1016 /$ j.fertnstert.2006.05.049

Ascoli M, Fanelli F, Segaloff DL. The leutropin/choriogonadotropin receptor, a 2002 perspective. Endocr Rev. 2002;23:141-74. PMID: 11943741 DOI: 10.1210/ edrv.23.2.0462

Balaban B, Urman B, Ata B, Isiklar A, Larman MG, Hamilton $\mathrm{R}$, Gardner DK. A randomized controlled study of human Day 3 embryo cryopreservation by slow freezing or vitrification: vitrification is associated with higher survival, metabolism and blastocyst formation. Hum Reprod. 2008;23:1976-82. PMID: 18544577 DOI: $10.1093 /$ humrep/den222

Beckers NG, Macklon NS, Eijkemans MJ, Ludwig M, Felberbaum RE, Diedrich K, Bustion S, Loumaye $E$, Fauser BC. Nonsupplemented luteal phase characteristics after the administration of recombinant human chorionic gonadotropin, recombinant luteinizing hormone, or gonadotropin-releasing hormone (GnRH) agonist to induce final oocyte maturation in in vitro fertilization patients after ovarian stimulation with recombinant follicle-stimulating hormone and GnRH antagonist cotreatment. J Clin Endocrinol Metab. 2003;88:4186-92. PMID: 12970285 DOI: 10.1210/jc.2002-021953

Bodri D, Guillén JJ, Galindo A, Mataró D, Pujol A, Coll O. Triggering with human chorionic gonadotropin or a gonadotropin-releasing hormone agonist in gonadotropin-releasing hormone antagonist-treated oocyte donor cycles: findings of a large retrospective cohort study. Fertil Steril. 2009;91:36571. PMID: 18367175 DOI: 10.1016/j.fertnstert.2007.11.049
Casarini L, Lispi M, Longobardi S, Milosa F, La Marca A, Tagliassacchi D, Pignatti E, Simoni M. LH and hCG action on the same receptor results in quantitatively and qualitatively different intracellular signaling. PLoS One. 2012;7:e46682. PMID: 23071612 DOI: 10.1371/journal. pone. 0046682

Castillo JC, Garcia-Velasco J, Humaidan P. Empty follicle syndrome after GnRHa triggering versus hCG triggering in COS. J Assist Reprod Genet. 2012;29:249-53. PMID: 22237554 DOI: $10.1007 / \mathrm{s} 10815-011-9704-8$

Cerrillo M, Rodríguez S, Mayoral M, Pacheco A, Martínez-Salazar J, Garcia-Velasco JA. Differential regulation of VEGF after final oocyte maturation with GnRH agonist versus hCG: a rationale for OHSS reduction. Fertil Steril. 2009;91:1526-8. PMID: 18990367 DOI: 10.1016/j. fertnstert.2008.08.118

Chambers GM, Wand H, Macaldowie A, Chapman MG, Farquhar CM, Bowman $M$, Molloy $D$, Ledger W. Population trends and live birth rates associated with common ART treatment strategies. Human Reprod. 2016;31:2632-41. PMID: 27664207 DOI: 10.1093/humrep/dew232

Craig J, Orisaka M, Wang H, Orisaka S, Thompson W, Zhu C, Kotsuji F, Tsang BK. Gonadotropin and intra-ovarian signals regulating follicle development and atresia: the delicate balance between life and death. Front Biosci. 2007;12:3628-39. PMID: 17485326 DOI: 10.2741/2339

Cruz M, Garrido N, Herrero J, Pérez-Cano I, Muñoz $M$, Meseguer M. Timing of cell division in human cleavage-stage embryos is linked with blastocyst formation and quality. Reprod Biomed Online. 2012;25:371-81. PMID: 22877944 DOI: 10.1016/j.rbmo.2012.06.017

Deepika K, Snehal D, Gautham P, Suvarna R, Amit U, Kamini R. Gonadotropin-releasing hormone agonist trigger is a better alternative than human chorionic gonadotropin in PCOS undergoing IVF cycles for an OHSS Free Clinic: A Randomized control trial. J Hum Reprod Sci. 2016;9:164-72. PMID: 27803584 DOI: 10.4103/09741208.192056

Delvigne A, Rozenberg S. Epidemiology and prevention of ovarian hyperstimulation syndrome (OHSS): a review. Hum Reprod Update. 2002;8:559-77. PMID: 12498425 DOI: $10.1093 /$ humupd/8.6.559

Devroey P, Polyzos NP, Blockeel C. An OHSS-Free Clinic by segmentation of IVF treatment. Hum Reprod. 2011;26:25937. PMID: 21828116 DOI: $10.1093 /$ humrep/der251

DiLuigi AJ, Engmann L, Schmidt DW, Maier DB, Nulsen JC, Benadiva CA. Gonadotropin-releasing hormone agonist to induce final oocyte maturation prevents the development of ovarian hyperstimulation syndrome in high-risk patients and leads to improved clinical outcomes compared with coasting. Fertil Steril. 2010;94:1111-4. PMID: 20074722 DOI: $10.1016 /$ j.fertnstert.2009.10.034

Eldar-Geva T, Zylber-Haran E, Babayof R, Halevy-Shalem T, Ben-Chetrit A, Tsafrir A, Varshaver I, Brooks B, Margalioth EJ. Similar outcome for cryopreserved embryo transfer following GnRH-antagonist/GnRH-agonist, GnRH-antagonist/ HCG or long protocol ovarian stimulation. Reprod Biomed Online. 2007;14:148-54. PMID: 17298715 DOI: 10.1016/ S1472-6483(10)60781-X 
Engmann L, Siano L, Schmidt D, Nulsen J, Maier D, Benadiva C. GnRH agonist to induce oocyte maturation during IVF in patients at high risk of OHSS. Reprod Biomed Online. 2006;13:639-44. PMID: 17169172 DOI: 10.1016/S14726483(10)60653-0

Engmann L, DiLuigi A, Schmidt D, Nulsen J, Maier D, Benadiva $\mathrm{C}$. The use of gonadotropin-releasing hormone $(\mathrm{GnRH})$ agonist to induce oocyte maturation after cotreatment with $\mathrm{GnRH}$ antagonist in high-risk patients undergoing in vitro fertilization prevents the risk of ovarian hyperstimulation syndrome: a prospective randomized controlled study. Fertil Steril. 2008;89:84-91. PMID: 17462639 DOI: 10.1016/j.fertnstert.2007.02.002

Engmann L, Benadiva C, Humaidan P. GnRH agonist trigger for the induction of oocyte maturation in GnRH antagonist IVF cycles: a SWOT analysis. Reprod BioMed Online. 2016;32:274-85. PMID: 26803205 DOI: 10.1016/j. rbmo.2015.12.007

Eppig JJ. FSH stimulates hyaluronic acid synthesis by oocyte-cumulus cell complexes from mouse preovulatory follicles. Nature. 1979;281:483-4. PMID: 492307 DOI: $10.1038 / 281483 \mathrm{a} 0$

Erb TM, Vitek W, Wakim AN. Gonadotropin releasing hormone agonist or human chorionic gonadotropin for final oocyte maturation in an oocyte donor program. Fertil Steril. 2010;93:374-8. PMID: 19171336 DOI: $10.1016 / j$.fertnstert.2008.12.015

Fauser BC, de Jong D, Olivennes F, Wramsby H, Tay C, Itskovitz-Eldor J, van Hooren HG. Endocrine profiles after triggering of final oocyte maturation with GnRH agonist after cotreatment with the GnRH antagonist ganirelix during ovarian hyperstimulation for in vitro fertilization. J Clin Endocrinol Metab. 2002;87:709-15. PMID: 11836309 DOI: 10.1210/jcem.87.2.8197

Fenwick J, Platteau P, Murdoch AP, Herbert M. Time from insemination to first cleavage predicts developmental competence of human preimplantation embryos in vitro. Hum Reprod. 2002;17:407-12. PMID: 11821286 DOI: 10.1093/ humrep/17.2.407

Garcia-Velasco JA. Agonist trigger: what is the best approach? Agonist trigger with vitrification of oocytes or embryos. Fertil Steril. 2012;97:527-8. PMID: 22222191 DOI: 10.1016/j.fertnstert.2011.12.010

Griesinger G, Diedrich K, Devroey $P$, Kolibianakis EM. $\mathrm{GnRH}$ agonist for triggering final oocyte maturation in the $\mathrm{GnRH}$ antagonist ovarian hyperstimulation protocol: a systematic review and meta-analysis. Hum Reprod Update. 2006;12:159-68. PMID: 16254001 DOI: 10.1093/ humupd/dmi045

Griesinger G, Kolibianakis EM, Papanikolaou EG, Diedrich $K$, Van Steirteghem A, Devroey P, Ejdrup Bredkjaer $\mathrm{H}$, Humaidan P. Triggering of final oocyte maturation with gonadotropin-releasing hormone agonist or human chorionic gonadotropin. Live birth after frozen-thawed embryo replacement cycles. Fertil Steril. 2007;88:616-21. PMID: 17451691 DOI: $10.1016 /$ j.fertnstert.2006.12.006
Gunby J, Bissonnette F, Librach C, Cowan L; IVF Directors Group of the Canadian Fertility and Andrology Society. Assisted reproductive technologies (ART) in Canada: 2007 results from the Canadian ART Register. Fertil Steril. 2011;95:542-7.e1-10. PMID: 20656287 DOI: 10.1016/j. fertnstert.2010.05.057

Gurbuz AS, Gode F, Uzman MS, Ince B, Kaya M, Ozcimen $\mathrm{N}$, Ozcimen EE, Acar A. GnRH agonist triggering affects the kinetics of embryo development: a comparative study. J Ovarian Res. 2016;9:22. PMID: 27059823 DOI: 10.1186/ s13048-016-0229-8

Herrero L, Pareja S, Losada C, Cobo AC, Pellicer A, Garcia-Velasco JA. Avoiding the use of human chorionic gonadotropin combined with oocyte vitrification and GnRH agonist triggering versus coasting: a new strategy to avoid ovarian hyperstimulation syndrome. Fertil Steril. 2011;95:1137-40. PMID: 21047635 DOI: $10.1016 /$ j.fertnstert.2010.09.040

Honnma $\mathrm{H}$, Hashiba $\mathrm{Y}$, Asada $\mathrm{Y}$, Endo T. Failure of triggering oocyte maturation with a GnRH agonist in polycystic ovary syndrome: two case reports. Eur ] Obstet Gynecol Reprod Biol. 2011;157:239-40. PMID: 21477915 DOI: 10.1016/j. ejogrb.2011.03.002

Hugues J. Ovarian stimulation for assisted reproductive Technologies. In: Vayena R, Rowe RJ, Griffin PD, eds. Current Practices and Controversies in Assisted Reproduction. Geneva: WHO; 2001. p. 102-25.

Human Fertilisation and Embryology Authority (HFEA). Fertility Treatment 2014: Trends and Figures. Fifth annual fertility. Finsbury Tower, London; 2016. Available at: https:// ifqtesting.blob.core.windows.net/umbraco-website/1783/ fertility-treatment-2014-trends-and-figures.pdf

Humaidan $\mathrm{P}$, Bredkjaer HE, Bungum L, Bungum M, Grøndahl ML, Westergaard L, Andersen CY. GnRH agonist (buserelin) or hCG for ovulation induction in GnRH antagonist IVF/ICSI cycles: a prospective randomized study. Hum Reprod. 2005;20:121320. PMID: 15760966 DOI: $10.1093 /$ humrep/deh765

Humaidan P, Papanikolaou EG, Tarlatzis BC. GnRHa to trigger final oocyte maturation: a time to reconsider. Hum Reprod. 2009;24:2389-94. PMID: 19608565 DOI: 10.1093/ humrep/dep246

Humaidan P, Quartarolo J, Papanikolaou EG. Preventing ovarian hyperstimulation syndrome: guidance for the clinician. Fertil Steril. 2010a;94:389-400. PMID: 20416867 DOI: $10.1016 /$ j.fertnstert.2010.03.028

Humaidan P, Ejdrup Bredkjaer H, Westergaard LG, Yding Andersen C. 1,500 IU human chorionic gonadotropin administered at oocyte retrieval rescues the luteal phase when gonadotropin-releasing hormone agonist is used for ovulation induction: a prospective, randomized, controlled study. Fertil Steril. 2010b;93:847-54. PMID: 19200959 DOI: $10.1016 /$ j.fertnstert.2008.12.042

Humaidan P, Kol S, Papanikolaou EG; Copenhagen GnRH Agonist Triggering Workshop Group. GnRH agonist for triggering of final oocyte maturation: time for a change of practice? Hum Reprod Update. 2011;17:510-24. PMID: 21450755 DOI: 10.1093/humupd/dmr008 
Humaidan P, Papanikolaou EG, Kyrou D, Alsbjerg B, Polyzos NP, Devroey $P$, Fatemi HM. The luteal phase after $\mathrm{GnRH}$-agonist triggering of ovulation: present and future perspectives. Reprod Biomed Online. 2012;24:134-41. PMID: 22197130 DOI: 10.1016/j.rbmo.2011.11.001

Humaidan $\mathrm{P}$, Polyzos NP, Alsbjerg B, Erb K, Mikkelsen AL, Elbaek HO, Papanikolaou EG, Andersen CY. GnRHa trigger and individualized luteal phase hCG support according to ovarian response to stimulation: two prospective randomized controlled multi-centre studies in IVF patients. Hum Reprod. 2013;28:2511-21. PMID: 23753114 DOI: $10.1093 /$ humrep/det249

Humaidan P, Alsbjerg B. GnRHa trigger for final oocyte maturation: is HCG trigger history? Reprod BioMed Online. 2014;29:274-80. PMID: 25043893 DOI: 10.1016/j. rbmo.2014.05.008

Humaidan P, Polyzos NP. Human chorionic gonadotropin vs. gonadotropin-releasing hormone agonist trigger in assisted reproductive technology-"The king is dead, long live the king!" Fertil Steril. 2014;102:339-41. PMID: 24907915 DOI: $10.1016 /$ j.fertnstert.2014.04.047

Iliodromiti S, Lan VT, Tuong HM, Tuan $\mathrm{PH}$, Humaidan $\mathrm{P}$, Nelson SM. Impact of GnRH agonist triggering and intensive luteal steroid support on live-birth rates and ovarian hyperstimulation syndrome: a retrospective cohort study. J Ovarian Res. 2013;6:93. PMID: 24369069 DOI: 10.1186/1757-2215-6-93

Imbar T, Kol S, Lossos F, Bdolah Y, Hurwitz A, Haimov-Kochman R. Reproductive outcome of fresh or frozen-thawed embryo transfer is similar in high-risk patients for ovarian hyperstimulation syndrome using $\mathrm{GnRH}$ agonist for final oocyte maturation and intensive luteal support. Hum Reprod. 2012;27:753-9. PMID: 22252086 DOI: 10.1093/ humrep/der463

$\mathrm{Kol} \mathrm{S}$. Luteolysis induced by gonadotropin-releasing hormone agonist is the key to prevention of ovarian hyperstimulation syndrome. Fertil Steril. 2004;81:1-5. PMID: 14711532 DOI: $10.1016 /$ j.fertnstert.2003.05.032

Kolibianakis EM, Schultze-Mosgau A, Schroer A, van Steirteghem A, Devroey P, Diedrich K, Griesinger G. A lower ongoing pregnancy rate can be expected when GnRH agonist is used for triggering final oocyte maturation instead of hCG in patients undergoing IVF with GnRH antagonists. Hum Reprod. 2005;20:2887-92. PMID: 15979994 DOI: $10.1093 /$ humrep/dei150

Kopeika J, Thornhill A, Khalaf Y. The effect of cryopreservation on the genome of gametes and embryos: principles of cryobiology and critical appraisal of the evidence. Hum Reprod Update. 2015;21:209-27. PMID: 25519143 DOI: $10.1093 /$ humupd/dmu063

Lemmen JG, Agerholm I, Ziebe S. Kinetic markers of human embryo quality using time-lapse recordings of IVF/ICSI-fertilized oocytes. Reprod Biomed Online. 2008;17:385-91. PMID: 18765009 DOI: $10.1016 /$ S14726483(10)60222-2
Maheshwari A, Pandey S, Shetty A, Hamilton M, Bhattacharya S. Obstetric and perinatal outcomes in singleton pregnancies resulting from the transfer of frozen thawed versus fresh embryos generated through in vitro fertilization treatment: a systematic review and meta-analysis. Fertil Steril. 2012;98:368-77.e1-9. PMID: 22698643 DOI: 10.1016/j.fertnstert.2012.05.019

Melo M, Busso CE, Bellver J, Alama P, Garrido N, Meseguer $\mathrm{M}$, Pellicer A, Remohí J. GnRH agonist versus recombinant HCG in an oocyte donation programme: a randomized, prospective, controlled, assessor-blind study. Reprod Biomed Online. 2009;19:486-92. PMID: 19909588 DOI: 10.1016/j.rbmo.2009.06.001

Nastri CO, Teixeira DM, Moroni RM, Leitão VM, Martins WP. Ovarian hyperstimulation syndrome: pathophysiology, staging, prediction and prevention. Ultrasound Obstet Gynecol. 2015;45:377-93. PMID: 25302750 DOI: 10.1002/uog.14684

Nevo O, Eldar-Geva T, Kol S, Itskovitz-Eldor J. Lower levels of inhibin $A$ and pro-alphaC during the luteal phase after triggering oocyte maturation with a gonadotropin-releasing hormone agonist versus human chorionic gonadotropin. Fertil Steril. 2003;79:1123-8. PMID: 12738506 DOI: 10.1016/S0015-0282(03)00177-8

Papanikolaou EG, Pozzobon C, Kolibianakis EM, Camus M, Tournaye H, Fatemi HM, Van Steirteghem A, Devroey P. Incidence and prediction of ovarian hyperstimulation syndrome in women undergoing gonadotropin-releasing hormone antagonist in vitro fertilization cycles. Fertil Steril. 2006;85:112-20. PMID: 16412740 DOI: $10.1016 / j . f e r t n-$ stert.2005.07.1292

Rezazadeh Valojerdi M, Eftekhari-Yazdi P, Karimian L, Hassani $F$, Movaghar $B$. Vitrification versus slow freezing gives excellent survival, post warming embryo morphology and pregnancy outcomes for human cleaved embryos. J Assist Reprod Genet. 2009;26:347-54. PMID: 19513822 DOI: $10.1007 / \mathrm{s} 10815-009-9318-6$

Roque M, Lattes K, Serra S, Solà I, Geber S, Carreras R, Checa MA. Fresh embryo transfer versus frozen embryo transfer in in vitro fertilization cycles: a systematic review and meta-analysis. Fertil Steril. 2013;99:156-62. PMID: 23040524 DOI: $10.1016 /$ j.fertnstert.2012.09.003

Rotterdam ESHRE/ASRM-Sponsored PCOS Consensus Workshop Group. Revised 2003 consensus on diagnostic criteria and long-term health risks related to polycystic ovary syndrome. Fertil Steril. 2004;81:19-25. PMID: 14711538 DOI: $10.1016 /$ j.fertnstert.2003.10.004

Seyhan A, Ata B, Polat M, Son WY, Yarali H, Dahan MH. Severe early ovarian hyperstimulation syndrome following $\mathrm{GnRH}$ agonist trigger with the addition of 1500 IU hCG. Human Reprod. 2013;28:2522-8. PMID: 23633553 DOI: $10.1093 /$ humrep/det124

Shapiro BS, Daneshmand ST, Garner FC, Aguirre M, Ross R. Comparison of human chorionic gonadotropin and gonadotropin-releasing hormone agonist for final oocyte maturation in oocyte donor cycles. Fertil Steril. 2007;88:237-9. PMID: 17296193 DOI: 10.1016/j.fertnstert.2006.11.069 
Sismanoglu A, Tekin HI, Erden HF, Ciray $\mathrm{NH}$, Ulug U, Bahceci M. Ovulation triggering with $\mathrm{GnRH}$ agonist vs. hCG in the same egg donor population undergoing donor oocyte cycles with GnRH antagonist: a prospective randomized cross-over trial. J Assist Reprod Genet. 2009;26:251-6. PMID: 19629674 DOI: 10.1007/ s10815-009-9326-6

Şükür YE, Özmen B, Özdemir ED, Seval MM, Kalafat E, Sönmezer M, Berker B, Aytaç R, Atabekoğlu CS. Final oocyte maturation with two different GnRH agonists in antagonist co-treated cycles at risk of ovarian hyperstimulation syndrome. Reprod Biomed Online. 2017;34:5-10. PMID: 27771155 DOI: 10.1016/j. rbmo.2016.10.004

Takahashi K, Mukaida T, Goto T, Oka C. Perinatal outcome of blastocyst transfer with vitrification using cryoloop: a 4-year follow-up study. Fertil Steril. 2005;84:88-92. PMID: 16009162 DOI: 10.1016/j.fertnstert.2004.12.051

Toner JP, Coddington CC, Doody K, Van Voorhis B, Seifer DB, Ball DG, Luke B, Wantman E. Society for Assisted Reproductive Technology and assisted reproductive technology in the United States: a 2016 update. Fertil Steril. 2016;106:541-6. PMID: 27301796 DOI: 10.1016/j.fertnstert.2016.05.026
Ulloa-Aguirre A, Crépieux P, Poupon A, Maurel MC, Reiter $\mathrm{E}$. Novel pathways in gonadotropin receptor signaling and biased agonism. Rev Endocr Metab Disord. 2011;12:25974. PMID: 21526415 DOI: 10.1007/s11154-011-9176-2

Van Landuyt L, Stoop D, Verheyen G, Verpoest W, Camus $M$, Van de Velde $H$, Devroey $P$, Van den Abbeel E. Outcome of closed blastocyst vitrification in relation to blastocyst quality: evaluation of 759 warming cycles in a single-embryo transfer policy. Hum Reprod. 2011;26:527-34. PMID: 21212054 DOI: 10.1093/humrep/deq374

Wong CC, Loewke KE, Bossert NL, Behr B, De Jonge CJ, Baer TM, Reijo Pera RA. Non-invasive imaging of human embryos before embryonic genome activation predicts development to the blastocyst stage. Nat Biotechnol. 2010;28:1115-21. PMID: 20890283 DOI: 10.1038/nbt.1686

Yding Andersen C, Westergaard LG, Figenschau Y, Bertheussen K, Forsdahl F. Endocrine composition of follicular fluid comparing human chorionic gonadotrophin to a gonadotrophin-releasing hormone agonist for ovulation induction. Hum Reprod. 1993;8:840-3. PMID: 8345072 DOI: $10.1093 /$ oxfordjournals.humrep.a138151

Yen SS, Llerena O, Little B, Pearson OH. Disappearance rates of endogenous luteinizing hormone and chorionic gonadotropin in man. J Clin Endocrinol Metab. 1968;28:17637. PMID: 5699949 DOI: $10.1210 /$ jcem-28-12-1763 